
STCLDioc

\section{External Morphology and Microstructure of the Compound Eye of Anomala Corpulenta Motsehulsky (Coleoptera: Rutelinae)}

International Journal of Opthalmology \& Eye Science (IJOES)

ISSN : 2332-290X

Research Article

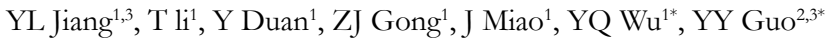 \\ ${ }^{1}$ Institute of Plant Protection, Henan Academy of Agricultural Sciences, Key Laboratory of Crop Pest Control of Henan Province, Zhengzhou, China. \\ ${ }^{2}$ State Key Laboratory for the Biology of Plant Diseases and Insect Pests, Institute of Plant Protection, Chinese Academy of Agricultural Sciences, \\ Beijing, China \\ ${ }^{3}$ College of Plant Protection, Northwest A\&F University, Yangling, Shaanxi, China
}

\title{
Abstract
}

In the current study, the external morphology and microstructure of the compound eyes of the scarab beetle Anomala corpulenta Motschulsky (Coleoptera: Rutelinae) were examined, and the regulatory mechanisms of light absorption were preliminarily identified. According to observations using electron microscopy and optical microscopes, the thickness of cornea of the compound eye was $>50 \mu \mathrm{m}$, which is thicker than found in most insect species $(<10 \mu \mathrm{m})$ and likely to provide protection to the eye when the insect is moving through the soil. The compound eyes of $A$. corpulenta are superposition eyes with a 'clear-zone', which is characterized by the migration of secondary iris and membrane pigment granules upon light/dark adaptation, the migration of basement membrane pigment particles from the proximal to distal ends of the eye, and the migration of secondary iris pigment granules into the clear-zone under light adaptation, which prevents light from being received during daytime. By contrast, the screening pigment granules were collectively clustered in distal interommatidial spaces around the cone and there was a basement membrane distribution of pigment granules in the proximal part of the eye, which would enable the eye to react to weak light levels.

Keywords: Anomala Corpulenta Motsehulsky; Compound Eye; Ommatidia; External Morphology; Microstructure.

\section{Introduction}

In insects, vision is one of the most important means of acquiring information about the external environment. It has a large role in finding hosts, intraspecific communication, for aging, escaping from predators, and in flight [1-4]. Therefore, understanding how an insect sees can be important when utilizing insects in research and for understandng their ecology. The compound eye is the main organ of insect vision, and most studies on insect vision have focused on the external morphology, internal microstructure, and functioning of the compound eye and the photoreceptors that it contains. Such information is important because it can affect various aspects of the functional ecology of an insect. For example, nocturnal insects, such as beetles and moths, have compound eyes with larger ommatidia or wider 'clear-zones' compared with daytime-active insects [5-7]. The shape, size, and number of compound eyes vary substantially across insect species, sexes, and different developmental stages. Not only can the shape and size of the ommatidia differ between species or between sexes within the same species, but there are also regional specializations of ommatidia within different parts of a single compound eyes.

In recent years, there have been various studies of the compound eyes of important insect pests, such as Helicoverpa armigera, Ostrinia nubilalis, Leucania separata Walker, melolonthids, and Maladera spp., and predators such as Chrysopa pallens Ramber, and Harmonia axyridis (Pallas) [8-13]. The external shape, internal

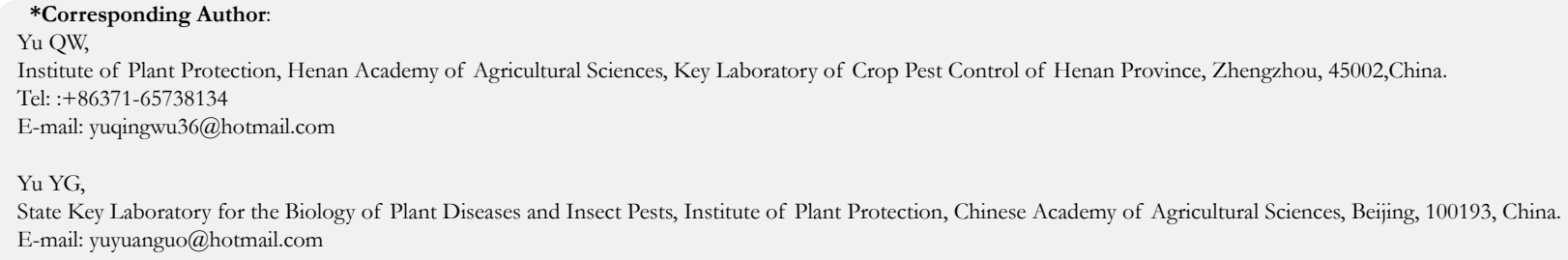

Copyright: YQ Wu, $\mathbf{Y Y ~ G u o}{ }^{\circ}$ 2016. This is an open-access article distributed under the terms of the Creative Commons Attribution License, which permits unrestricted use, distribution and reproduction in any medium, provided the original author and source are credited. 
microstructure, light sensitivity, and imaging mechanisms of compound eyes have been extensively studied from morphological, physiological, and optical perspective. Such studies have provided an important basis for understanding the role of the vision in, for example, insect feeding, mate finding, and habitat selection, as well as in terms of their use in integrated pest management schemes.

The scarab beetle, Anomala corpulenta Motschulsky (Coleoptera: Scarabaeoidea, Rutelinae), is a widespread and destructive pest in China [14]. The larvae feed on the underground roots and storage organs of crops, with a preference for peanuts and soybeans, whereas the adults feed on the leaves of various species of fruit and forest trees. Little is known about the compound eye of this important pest species; therefore, the current study investigated the morphology of the compound eye of $A$. corpulenta and the effects of light/dark adaptation on its microstructure. Such basic information can be used to lay the foundation not only for further research into the photosensitive mechanisms, photosensitive behaviors, biological communication, visual electrophysiology, and photosensitive receptor molecular biology of this species, but also for the comprehensive management of this economically important pest.

\section{Material and Methods}

\section{Study insects}

Anomala corpulenta used in the study were taken from a laboratory population that had originally been collected during the summer of 2012 in the Yuanyang Experimental Station $\left(113.46^{\circ} \mathrm{E}\right.$; $\left.35.08^{\circ} \mathrm{N}\right)$, Henan Academy of Agricultural Sciences, Henan Province, China. The insects used in the experiment were 1-2-week-old adults.

\section{External morphology of the compound eyes of $A$. corpu- lenta}

The heads of the experimental specimens were split and washed in $70 \%$ ethanol. Any dirt on the surface of the compound eye was removed with ultrasonic oscillation. The specimens were then dehydrated in a graded series of ethanol (70\% ethanol for $10 \mathrm{~min}$, $80 \%$ ethanol for $10 \mathrm{~min}, 90 \%$ ethanol for $10 \mathrm{~min}, 95 \%$ ethanol for $10 \mathrm{~min}, 100 \%$ ethanol for $10 \mathrm{~min}$ ). The specimens were then dried with critical point drying and fixed to a sample table and coated with gold using a sputter coater (KYKY+ SBC-12, Ion sputtering instrument). The specimens were examined in a scanning electron microscope (S-3400, Hitachi Ltd), operated at $2 \mathrm{kV}$.

\section{Microstructure of the compound eye of $A$. corpulenta}

Light/dark adaptation experiments: Healthy and active adult A. corpulenta were grouped into two groups. Light-adapted (LA) individuals were beetles that were exposed to light for at least $2 \mathrm{~h}$ in a light incubator before decapitation. Dark-adapted (DA) individuals beetles that were kept in total darkness in a darkroom for at least $2 \mathrm{~h}$ before decapitation.

Internal microstructure of the compound eye of A. corpulenta: After light and dark adaptation, the heads of the experimental specimens were split and fixed in Bouin's fixative for 24 h. The specimens were then washed in $70 \%$ ethanol, dehydrated in a graded series of acetone, transparentized in a mixture of xylene and 100\% ethanol (1:1) for $10 \mathrm{~min}$, and then in xylene for 10 min and then wax dipped in a water bath for 3.5 h. Finally, the specimens were embedded in paraffin using a biological tissue embedding machine (KD-BNA, Zhejiang province Jinhua Kedi Instrument Equipment Co., Ltd.). Six $\mu \mathrm{m}$-thick sections were cut with a KD2258 slicer (Jinhua Kedi Instrument Equipment Co., Ltd), The sections were then stained with hematoxylin and eosin (H\&E) and mounted with neutral gum. Sections were observed under a fluorescence microscope (80i, Nikon) and measurements taken using a camera.

\section{Statistical analysis}

A Mann-Whitney $U$ test was applied to determine whether differences in anatomical parameters between male and female eyes were statistically significant $(\mathrm{P}<0.05)$. Statistical analyses were performed using the software SPSS16.0.

\section{Results}

\section{External morphology of the compound eye of $A$. corpulenta}

The heart-shaped compound eyes of $A$. corpulenta occupied lateral positions on either side of the head. Male and female eyes had approximately 4543 and 4701 ommatidia, respectively (Table 1, Figure. 1A). The compound eye was connected to the head via a protrusion that was covered with sensory hairs, was firm to touch, and reached the basement membrane (Figure. 1B). The ocular surface of the compound eye was reticulate, and ommatidia were

Table 1. Anatomical parameters of the eyes of $A$. corpulenta.

\begin{tabular}{|c|c|c|c|c|c|c|}
\hline Parameter & Unit & $\mathrm{n}$ & male & female & $\mathrm{Z}$ & $\mathrm{P}$ \\
\hline Number of facets per eye & - & 3 & $4543.33 \pm 34.80 \mathrm{a}$ & $4701.67 \pm 70.73 \mathrm{a}$ & -1.508 & 0.127 \\
\hline Corneal thickness & $\mu \mathrm{m}$ & 16 & $54.07 \pm 1.82 \mathrm{a}$ & $50.64 \pm 3.50 \mathrm{a}$ & -0.452 & 0.651 \\
\hline Corneal diameter & $\mu \mathrm{m}$ & 8 & $19.58 \pm 0.40 \mathrm{a}$ & $20.28 \pm 0.65 \mathrm{a}$ & -0.95 & 0.345 \\
\hline Cone length & $\mu \mathrm{m}$ & 26 & $56.69 \pm 0.89 \mathrm{a}$ & $52.57 \pm 2.38 \mathrm{a}$ & -1.089 & 0.276 \\
\hline Cone diameter & $\mu \mathrm{m}$ & 11 & $14.34 \pm 0.13 \mathrm{a}$ & $15.22 \pm 0.41 \mathrm{a}$ & -1.973 & 0.053 \\
\hline retinula cells column length & $\mu \mathrm{m}$ & 30 & $143.75 \pm 6.92 \mathrm{a}$ & $147.79 \pm 7.90 \mathrm{a}$ & -0.163 & 0.871 \\
\hline Rhabdom length & $\mu \mathrm{m}$ & 26 & $94.12 \pm 1.80 \mathrm{a}$ & $91.69 \pm 4.20 \mathrm{a}$ & -0.3 & 0.976 \\
\hline
\end{tabular}

Data are expressed as mean \pm standard error. 
Figure 1. External morphology of $A$. corpulenta compound eye .

A: frontal view of the eye of A.corpulenta. B: The special structure of compound. C: The dorsal eye region of compound eye. D: The center area of compound eye.

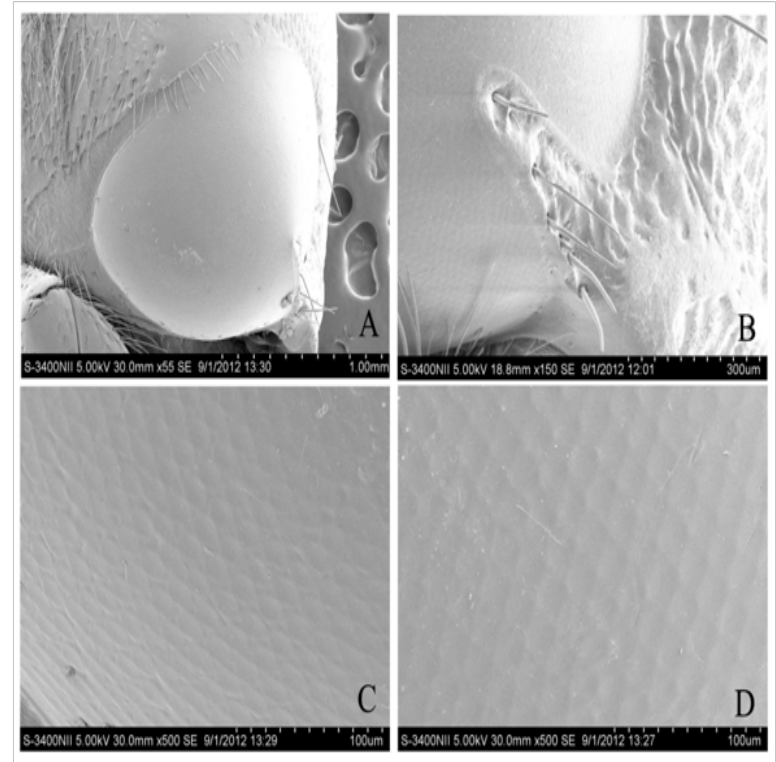

Figure 2. Longitudinal section of the compound eye in $A$. corpulenta.

A, C, D: Light adapted condition. B: Dark adapted condition. A, B: C Cornea; CC Crystalline cones; CZ Clear-zone; RCC Retinula cell column; RH Rhabdom; BM Basement membrance. C: The arrow shows special structure. D: The arrow shows longitudinal setions of crystalline cones. Scale bars: $A$ and $C=100 \mu \mathrm{m}, B$ and $D=50 \mu \mathrm{m}$.
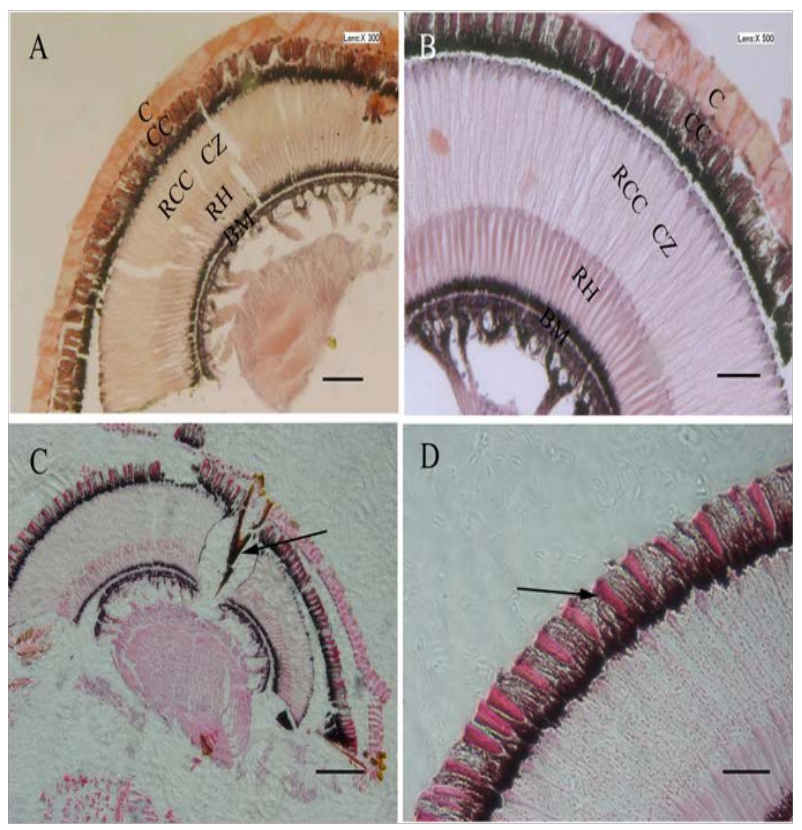

generally diamond in shape in all areas of the eye (Figure. 1C, D). The center of each ommatidium was slightly concave.

General organization of the compound eye of $A$. corpulenta

Ommatidium structure: As can be seen from the transverse and longitudinal characteristics of the compound eye at different depths, $A$. corpulenta had a classic superposition eye design that is characteristic of most nocturnal insects. The eyes of both sexes shared the same overall cellular organization of the ommatidium. Each ommatidium featured a dioptric apparatus, a clear-zone, eight retinula cells that form a centrally fused rhabdom, and one basal cell (Figure. 2A-C).

Dioptric apparatus: The dioptric apparatus comprised mainly the cornea and crystalline cone. Corneal ommatidia were located in the outermost layer, composed of multilayer disk fibers and with a convex lens that had an inner convex edge (Figures. 2,3). The corneal thickness near the center of the eye was 54.07 and $50.64 \mu \mathrm{m}$ in males and females, respectively, although the difference was not statistical significant (Table 1). A transverse section of the cornea shows its almost hexagonal shape, with a diameter of 19.58 and $20.28 \mu \mathrm{m}$ in males and females, respectively. 
Figure 3. Transverse section of the conca and crystalline cone cell of the compound eye in $A$. corpulenta. A: The conca. B: The crystalline cone cell. The arrow shows the crystalline cone, The line shows pigment cells. Scale bars: $\mathrm{A}=20 \mu \mathrm{m}, \mathrm{B}=10 \mu \mathrm{m}$.
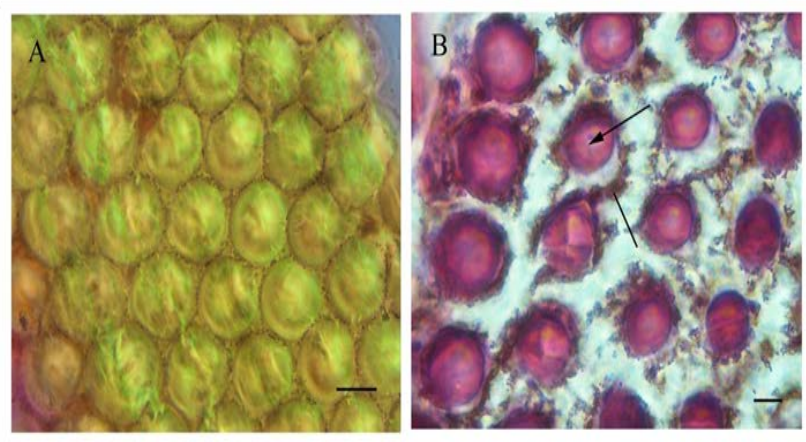

The conical cone refraction device (Figures. 2D, 3B) was located below the cornea. Cones were 56.69 and $52.57-\mu \mathrm{m}$ long in males and females, respectively. The cone was circular in cross-section, with a diameter of 14.34 and $15.22 \mu \mathrm{m}$ in males and females, respectively (Table 1$)$. There were no statistically significant differences between the sexes in terms of cone length or diameter. Two divisions or four divisions situation can be appeared in cones (Figure. 3B). Pigment particles increased in number from the distal to the proximal end of the cone.

\section{Photoreceptors:}

Retinula cell column: The retinula cell body close to the crystalline cone in the distal part of the rhabdom was gathered into a bundle with ommatidia, forming the retinula cell column. It measured $143.75 \mu \mathrm{m}$ in males, which was not significantly shorter than in females $(147.79 \mu \mathrm{m})$ (Table 1$)$. There were eight retinula cells within each ommatidium. The longitudinal and transverse planes were visible, and each retinula cell column had six retinula cells, with cyclic aggregates to the round of cone parts. From a transverse angle, each retinula cell was surrounded by seven adjacent retinula cells, forming a hexagonal structure. The distal nucleus cross-section measured the most, followed by the middle and basal cross-sections (Figure. 4A-C). Pigment granules were distributed in the retinula cells (Figure. 4D).

Rhabdom: The rhabdom is a long structure comprising many small slender rod groups, located in the center of the lesser omentum, and is the main photosensitive area. The rhabdomere is a light-sensing device characterized by retinula cells and the inner wall of the rhabdomere, which comprises microtubules arranged in rows. Its long axis was perpendicular to the long axis of the rhabdom [15].

Rhabdoms were $94.12 \mu \mathrm{m}$ and $91.69 \mu \mathrm{m}$ long in male and female eyes, respectively, but the difference was not statistically significant (Table 1). The rhabdom appeared purple under H\&E staining. Cross-sections along the length of the rhabdomere showed that its shape varied along its length. For example, the distal end of the rhabdomere was an irregular polygon in shape (Figure. $5 \mathrm{~A})$, larger than the other parts of the rhabdomere and lacked any microtubules around it. The central retinula cell bodies were filled with microvilli, but given the large amount of microtubules present, this section of the rhabdomere was slightly smaller than the distal end (Figure. 5B). The section area of rhabdomere was the smallest, although each retinula cell body was occupied by microvilli, the number of tracheole was more than in the proximal rhabdomere (Figure. 5C).

Basement membrane: A basement membrane occurred at the bottom of each ommatidium, and had a palisade structure. According to previous research, the basement membrane provides mechanical support to the fixed ommatidium in addition to separate ommatidium from the internal optic lobe. Several axon bundles were grouped into larger bundles reaching through the basement membrane and into the optic ganglion. A serried tracheole also extended from the omentum through the basement membrane. Dense, dark-staining pigment granules were distributed in both sides of the basement membrane, with a diffusion of pigment particles between the membrane and the lower segment of the rhabdom (Figure. 6).

Unique structure: In addition to the commonly found structures within insect compound eyes (cornea, crystalline cone, retinula cells, retinal rods, basement membrane and the tracheole), $A$. corpulenta also had a triangular pyramid structure in the back of the compound eye connected to the head capsule. The structure reached deep into the basement membrane (Figure. 1E).

\section{Sensoric changes to $L A$ and DA:}

The migration of pigment granules: The compound eyes of A. corpulenta showed pronounced pigment translocation upon LA and DA. In LA eyes, the pigment granules from the basement membrane invaded the rhabdom from the proximal to distal region. In DA eyes, the membrane pigment diffused from the distal to proximal region of the rhabdom, becoming evenly distributed in its proximal region (Figure. 7). No obvious movement of pigment granules was found within the primary pigment cells under different light and dark conditions.

The migration of secondary iris pigment particles: Secondary iris pigment particle invasion of the 'clear-zone' in the distal region of the retinula cell column from the crystalline cone region occurred under LA conditions (Figure. 8B). In eyes from DA insects, secondary iris pigment particles remained in the crystalline cone (Figure. 8A), resulting in a 'clear-zone' without pigment particles and a wider proximal taper compared with LA eyes, allowing more light to enter the eye. 
Figure 4. The retinula cell of the compound eye in $A$. corpulenta.

A: Transverse section of the distal end of retinal cell column. The arrow shows retinula cell column. B: Transverse section of the middle of retinal cell column. The arrow shows retinula cell column. D: Transverse section of the proximal end of retinal cell column. The arrow shows retinula cell column. D: The retinula cell nucleus. The arrow shows retinula cell nucleus. Scale bars: A, B, C and D = $10 \mu \mathrm{m}$.
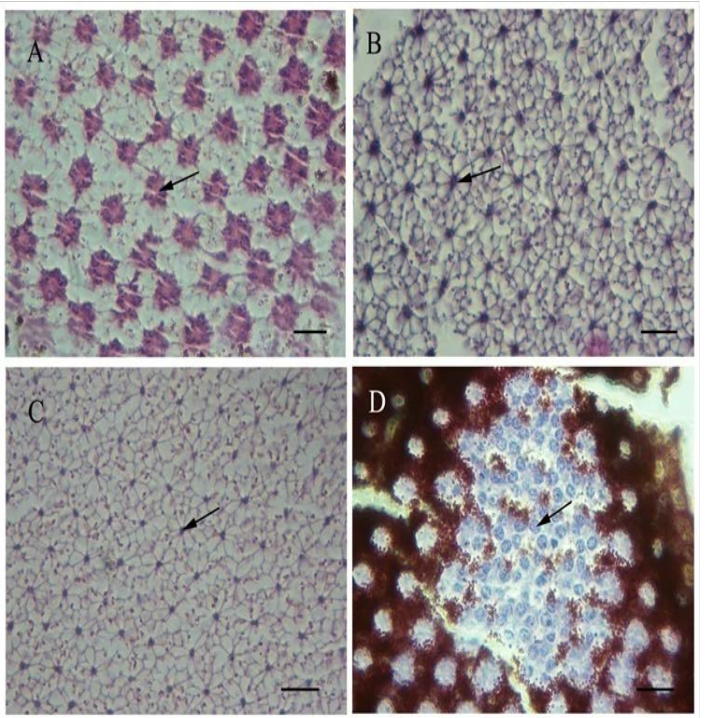

Figure 5. The rhabdom of the compound eye in $A$. corpulenta.

A: Transverse section of the distal end of rhabdom. The line shows rhabdom. The arrow shows tracheole. B: Transverse section of the middle of rhabdom. The line shows rhabdom. The arrow shows tracheole. C: Transverse section of the proximal end of rhabdom. The line shows rhabdom. The arrow shows tracheole. Scale bars: A, B and C=10 $\mu \mathrm{m}$.
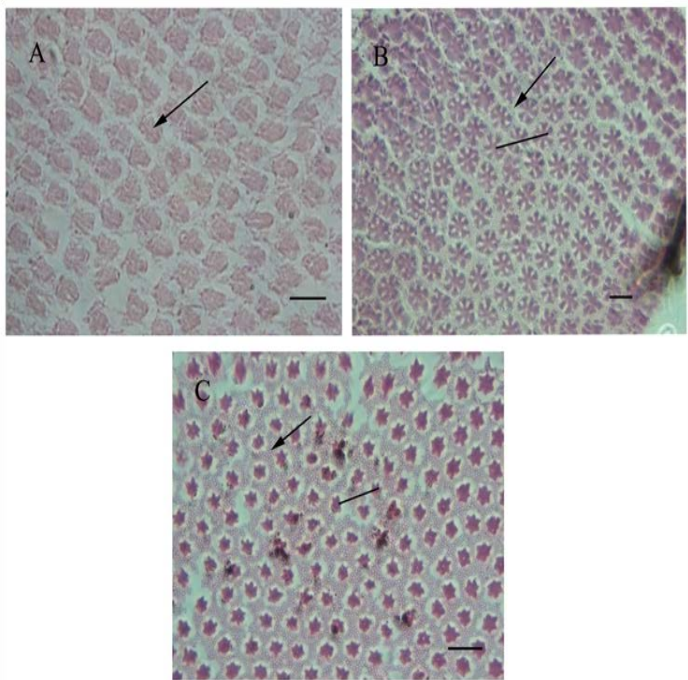

The effect of sex on the microstructure of the compound eyes: There was no significant difference in the structures of compound eyes from males and females under LA or DA conditions.

\section{Discussion}

General organization of the compound eye of $A$. corpulenta

The results of this study led us to conclude that the visual system of A. corpulenta is characteristic of nocturnal insects. Anomala corpulenta had morphological features characteristic of superposition eyes, in that the compound eyes occupied lateral positions on either side of the head and were heart shaped. Each compound eye comprised approximately 4543 and 4701 ommatidia in males and females, respectively. The center of each ommatidium was slightly concave. The ommatidial shape remained approximately the same regardless of its position in the eye. Depending on the environment that an insect inhabits, the ommatidial surface structure and density can vary significantly. For example, the surface of ommatidia in nocturnal insects is convex, whereas in daytime-active insects it is slightly flat [16]. Thus, the results of the current study are contradictory in that the ommatidia had slightly flat surfaces, even though $A$. corpulenta is a nocturnal insect. Thus, further research is required to clarify this result. The ommatidium of $A$. corpulenta were diamond in shape, which differs from that of most other insects $[12,13,17]$; however, the cornea was not hexagonal in cross-section, possibly because the outer protective layer of the cornea was thicker, preventing a hexagonal shape. 
Figure 6. The basement membrane of the compound eye in $A$. corpulenta.

A: Longitudinal section of the basement membrane. The line shows basement membrane. The arrow shows tracheole. B: Transverse section of the basement membrane. The line shows basement membrane. The arrow shows tracheole. Scale bars: $A$ and $B=10 \mu \mathrm{m}$.

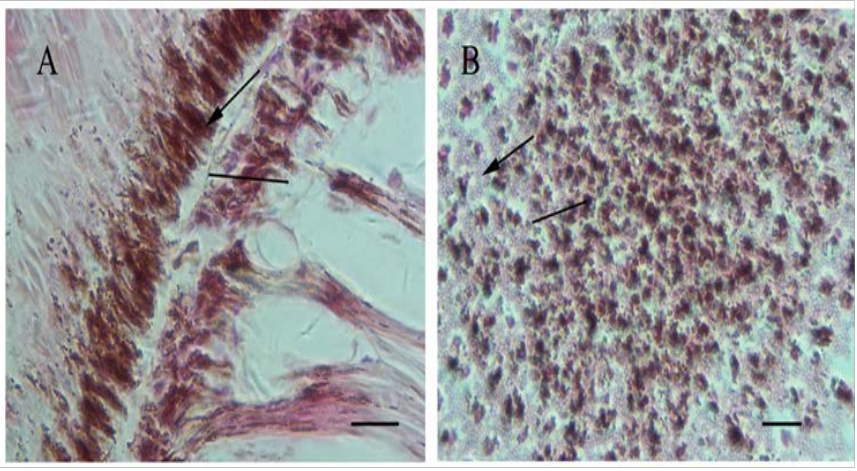

Figure 7. Longitudinal section of the secondary iris pigment granule at basement membrane under light and dark adapted A: Dark adapted condition. The arrow shows the clear-zone. B: Light adapted condition. The arrow shows the secondary iris pigment granule. Scale bars: $A=50 \mu \mathrm{m}, B=100 \mu \mathrm{m}$.
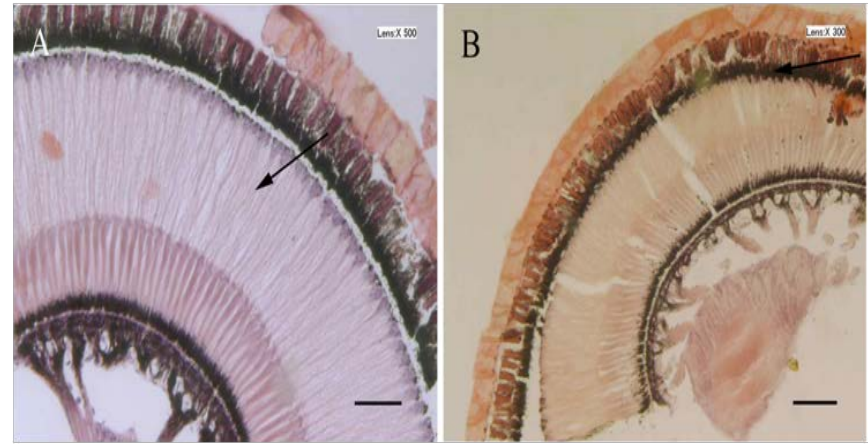

Figure 8. Longitudinal section of the iris granule at basement membrane under light and dark adapted. A: Dark adapted condition. B: Light adapted condition. The arrow shows iris granule. Scale bars: $\mathrm{A}$ and $\mathrm{B}=50 \mu \mathrm{m}$.
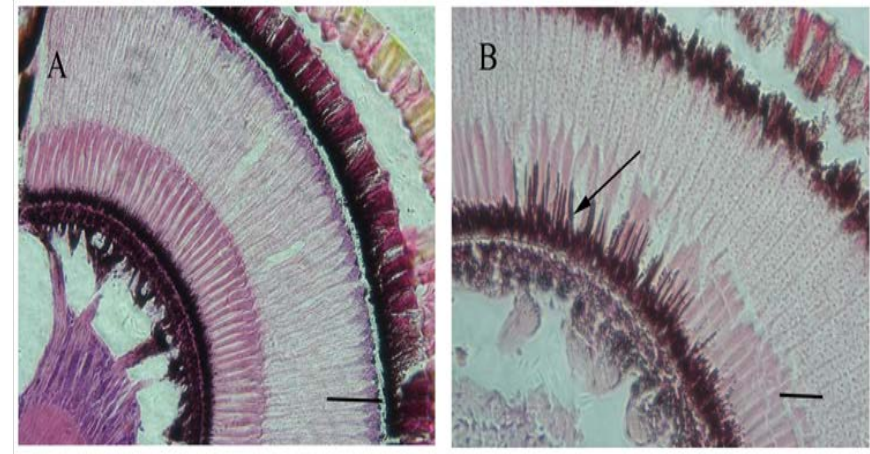

The corneal surface of the compound eye in many insects has special structures that adapt it to the environment that the insect inhabits. For example, in flies, the outer surface of the cornea has stinging hairs [18], whereas ants have branching bristle tips [16]; in other species, the outer surface of the cornea has tiny ridges or papilla [19], whereas in crickets (Orthoptera, Gryllidae), it has mechanoreceptive hairs and bell-shaped sensilla $[18,19]$. The surface of compound eyes in most nocturnal Lepidoptera is covered with small round convex uniform particles, with the corneal mastoid in the center, a special concave-convex structure that reduces light reflection, enhances light absorption, and prevents the entry of foreign matter [20]. In the current study, there was no corneal mastoid on the surface of the compound eye of $A$. corpulenta, only a protruding tissue that connected to the head capsule below the eyes, and that was covered in short hairs. This structure is similar to that found in Maladera orientalis Motschulsky [16]. The protruding tissue might be a structure that has evolved in response to life underground by protecting the compound eyes from soil, sand, and other foreign particles. It was unclear whether the short hairs were connected to the sensory nerve, and so this requires further research. The structure is likely to be a common feature of the compound eyes of coleopterans, although whether it can be used for species identification requires further investigation.

\section{Internal microstructure}


According to the cross-sections taken of the compound eye, each ommatidium comprised the dioptric apparatus, the retinula cell column, retinal rods and basement membrane. In addition, $A$. corpulenta had a pyramid structure in the back of the compound eye, connected to the head capsule and reaching deep into the basement membrane. Anomala corpulenta has a refracting superposition eye, which is an eye type typical of nocturnally active insects. A 'clear zone' between the rhabdom and cone allows light to enter the eye and be focused on more or less a single photoreceptor in the retina [21]. Thus, superposition eyes can collect more light compared with apposition eyes without having to sacrifice resolving power. However, mobile primary iris pigments were not found in this study.

Adult $A$. corpulenta spend most of their lives in the surface layer of the soil, exposing their eyes to soil, sand, and other hard particles. Thus, their compound eyes have evolved a thick outer layer to protect the eye from the soil. As can be seen from the longitudinal sections, the corneal thickness was approximately 50 $\mu \mathrm{m}$, providing a thick protective layer over the internal structures of the eye in $A$. corpulenta. A similar structural layout was reported from $M$. orientalis [16] and the dung beetle Onthophagus posticus [22], with corneal thicknesses of approximately $40 \mu \mathrm{m}$ and $35 \mu \mathrm{m}$, respectively. By contrast, the corneal thicknesses of the lepidopteran Acentria ephemerella [23] and Acleris fimbriana [24] were approximately $8 \mu \mathrm{m}$ and $7 \mu \mathrm{m}$, respectively, indicating the different adaptations of the compound eye to different habitats. As can be seen from the cross section of the retinal cell column, the density of the retinula cell column was larger than that of the crystalline cone. The crystalline cone of each ommatidium was connected by four to six retinula cells. The density of the retinula cell column was smaller, with more space between each retinula cell. The retinula cell column was widest in the center. The retinula cells in the retinal rod were grouped into specialized microvilli to form the rhabdom. From the cross section of the retinal cell column, we could see a structure characterized by seven retinula cells forming a hexagonal structure with one cell in the center and plasmodesmata connecting each cell (Figure. 4A-C). These plasmodesmata might have a mechanical support role or function in photon signal transmission between cells. A similar structure has been found in the dung beetle [22] and M. orientalis [16].

\section{Functional adaptation of the compound eye}

The compound eyes of male and female $A$. corpulenta underwent similar photomechanical changes in response to LA and DA, namely the migration of secondary pigment granules and local mobilization of basement membrane pigment granules. This light regulation mechanism has also been found in other insect species with superposition eyes $[12,16]$. The distribution of membrane pigment granules was wider in retinal rods under LA compared with DA. The function of these pigment granules might be to absorb light that is not completely absorbed by the superior pigment. Basement membrane pigment granules spread farther and showed stronger absorbent ability with increasing light intensity, ensuring accurate transmission of the light signal along the rhabdom axon. Although $A$. corpulenta is a nocturnal species, there was no obvious movement of pigment granules found within the primary iris pigment cells. This result might be related to activity in a weak light environment or poor light sensitivity.

\section{Polarized light}

As other studies have shown, beetles that respond to polarized light have the same basic arrangement of retinula cells and microvilli on a longer rhabdom, a reflecting tracheal layer, and the loss of secondary iris pigment cells [25]. Such characteristics ensure that nocturnal insects emerge during the evening for foraging and mating activities. The results of the current study showed that $A$. corpulenta has longer rhabdoms and retinula cells in a petal-shaped array in the retinula cell column. The features could explain the sensitivity of $A$. corpulenta adults to polarized light. However, additional work is required to investigate this hypothesis further.

\section{Acknowledgments}

This work was supported by the China Agricultural Research System (CARS-03) and Henan academy of agricultural sciences of independent innovation fund (2015).

\section{References}

[1]. Moericke V (1955) Uber die Lebensgewohnheiten der geflugelten Blattlause (Aphidina) unter besonderer Berucksichtigung desVerhaltens beim Landen. Zeitschrift fur Angewandte Entomologie. 37(1): 29-91.

[2]. Dixon AFG(1985) Aphid Ecology. Blackie, Glasgow, London.

[3]. Chapman RF, Bernays EA, Simpson SJ (1981) Attraction and repulsion of the aphid, Cavariella aegopodii by plant odours. J Chem Ecol. 7(5): 881888.

[4]. Egelhaaf M, Kern R (2002) Vision in flying insect. Curr Opin Neurobiol. 12(6): 699-706.

[5]. Caveney S, Mcintyre P (1981) Design of graded-index lenses in the superposition eyes of scarab beetles. Phil. Trans. Soc. Lond. (B). 294: 589-632.

[6]. Jander U, Jander R (2002) Allometry and resolution of bee eyes (Apoidea). Arthrop Struct Dev. 30(3): 179-193.

[7]. Moser JC, Reeve JD, Bento JMS, Lucia TMC, Cameron RS, Heck NM (2004) Eye size and behaviour of day- and night-flying leafcutting ant alates. J Zool Lond. 264(1): 69-75.

[8]. Horridge GA, Giddings C, Stange G(1972) The superposition eye of skipper butterflies. Proceedings of the Royal Society of London, Biological Sciences. 182: 457- 495.

[9]. George CS, Harold K (1976) The ultrastructural organization of the visual system of the wax moth, Galleria mell onella : The retina. Cell Tiss Res. 174(4): 519- 531.

[10]. Image Recognizing Group \& Shanghai Physiological Institute(1976) Fine structure of photoreceptor of compound eye in nocturnal moth. Progress in Biochemistry and Biophysics. 3: 27-30.

[11]. Wu WG, Horridge GA (1988) Rhythmic changes in physiology and structure of the compound eye of migratory locust. Acta Entomologica Sinica. $31: 341-345$.

[12]. Zhang HQ, Zhu N, Fan F, Wei GS (2007) External morphology and microstructure of the compound eye of Chrysopa pallens Ramber ( Neuroptera: Chrysopidae). Acta Entomologica Sinica. 50(5): 454- 460.

[13]. Wu CJ, Chen J, Fan F, Qin QJ, He YZ (2011) External morphology, microstructure and light/dark adaptational changes of the compound eyes of Harmonia axyridis ab.conspicua(Coleoptera: Coccinellidae). Acta Entomologica Sinica. 54(11): $1274-1280$.

[14]. Li WZ, Yuan YH, Yuan GH, Luo MH, Guo XR (2009) Selection and feeding responses of Anomala corpulenta adults to different plant leaves. Chinese Journal of Ecology. 28: 1905-1908.

[15]. Jin F, Yan ZC (2012) The compound eyes of insects. Bulletin of Biology. 47: 4-6.

[16]. Lv F (2012) Study on Microstructure of the Compound Eye and Phototactic and Colour Behavior of Maladera orientalis Motsch (Coleoptera: Scarabaeidae).

[17]. Guo BQ (1988) Fine structure of regional variation of the compound eye of Heliothis armigera (Hbner). Acta Entomologica Sinica. 31 : 165- 170.

[18]. Bertha FA, Dicke AW (1974) Surface structure of the compound eye various drosophila species and eye mutants of Drosophila melanogaster [J]. Theor Applied Genet. 44: 262-265.

[19]. Leng X, Na J (2009) Structure and function of insect compound eyes. Jour- 
nal of Shenyang Normal University ( Natural Science). 27 : 241-244.

[20]. Chen WZ, Yang SX, Li SM, Yang LJ (2002) A comparative study on the surface ultrastructure of ommatidium in butterflies. Acta Entomologica Sinica. 45(1): 35-40.

[21]. Land MF (1981) Optics and vision in invertebrates. In: Autrum H, Handbook of Sensory Physiology. Vision in Invertebrates: Berlin, Heidelberg, NewYork.

[22]. Gokan N, Meyer-rochow VB (1990) The compound eye of the dung beetle, Onthophagusposticus. (Coleoptera:Scarabaeidae). New Zealand Entomologist. 13: 7-15.

[23]. Ting FL, Elisabeth MG, Victor BMR (2007) Sexual dimorphism and light/dark adaptation in the compound eyes of male and female Acentria ephemerella (Lepidoptera: Pyraloidea: Crambidae). Eur J Entomol. 104(3): 459-470.

[24]. Zhang L (2010) Study on external morphology and microstructure of the compound eye of the moth, Acleris fimbriana Thun-berg [D]. Hebei Agricultural University, Hebei.

[25]. Marie D, Peter N, Clarke HS (2003) Twilight orientation to polarized light in the crepuscular dung beetle Scarabaeus zambesianus. J Exp Biol. 206: 1535-1543.

\section{Special Issue on}

"Eyes and Light Science"

$$
\text { Edited by: }
$$

Josef Troger, University of Innsbruck, Austria. E-mail: Josef.troger@i-med.ac.at 